\title{
Fetal Cardiac Intervention for Pulmonary Atresia with Intact Ventricular Septum: International Fetal Cardiac Intervention Registry
}

\author{
Whitnee J. Hogan ${ }^{a}$ Sofia Grinenco ${ }^{b}$ Aimee Armstrong ${ }^{c}$ Roland Devlieger ${ }^{d}$ \\ Joanna Dangel ${ }^{\mathrm{e}}$ Queralt Ferrer $^{\mathrm{f}}$ Michele Frommelt ${ }^{\mathrm{g}}$ Alberto Galindo $^{\mathrm{h}}$ \\ Helena Gardiner ${ }^{i}$ Sarah Gelehrter ${ }^{j} \quad$ Ulrike Herberg ${ }^{k}$ Lisa Howley' \\ Edgar Jaeggi ${ }^{m}$ Joana Miranda ${ }^{n}$ Shaine A. Morris ${ }^{\circ}$ Dick Oepkes ${ }^{p}$ \\ Simone Pedra ${ }^{q}$ Renuka Peterson ${ }^{r}$ Gary Sholler ${ }^{\mathrm{s}}$ John Simpson ${ }^{\mathrm{t}}$ \\ James Strainic ${ }^{\mathrm{u}}$ Trisha V. Vigneswarran ${ }^{\mathrm{t}}$ Annette Wacker-Gussmann ${ }^{\mathrm{V}}$ \\ Anita J. Moon-Grady ${ }^{a}$ for the IFCIR Participants \\ a University of California-San Francisco, San Francisco, CA, USA; ${ }^{b}$ Hospital Italiano de Buenos Aires, Buenos Aires, \\ Argentina; ${ }^{C}$ Nationwide Children's Hospital, Columbus, OH, USA; ${ }^{d}$ Department of Obstetrics and Gynaecology, \\ University Hospitals KU Leuven, Leuven, Belgium; ${ }^{\mathrm{e}}$ Department of Perinatal Cardiology and Congenital Anomalies, \\ Centre of Postgraduate Medical Education, Warsaw, Poland; ${ }^{f}$ Vall d'Hebron Hospital, Barcelona, Spain; ${ }^{9}$ Children's

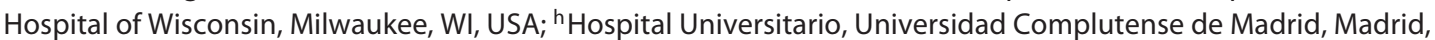 \\ Spain; 'The Fetal Center at Children's Memorial Hermann Hospital, Houston, TX, USA; ${ }^{j}$ C. S. Mott Children's Hospital, \\ University of Michigan, Ann Arbor, MI, USA; ${ }^{2}$ University of Bonn, Bonn, Germany; 'Children's Hospital Colorado, \\ Aurora, CO, USA; ${ }^{\mathrm{m}}$ Hospital for Sick Children, Toronto, ON, Canada; ${ }^{\mathrm{n}}$ Centro Hospitalar São João, Porto, Portugal; \\ ${ }^{\circ}$ Baylor College of Medicine, Houston, TX, USA; ${ }^{P}$ Leiden University Medical Center, Leiden, The Netherlands;

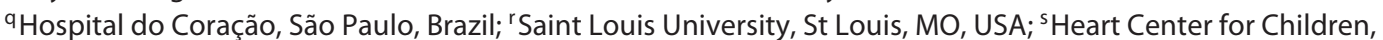 \\ Children's Hospital at Westmead and University of Sydney, Sydney, NSW, Australia; 'Evelina London Children's \\ Hospital, Guy's and St. Thomas' NHS Foundation Trust Hospitals, London, UK; ' Rainbow Babies and Children's \\ Hospital Division of Pediatric Cardiology, University Hospitals, Cleveland, OH, USA; ${ }^{v}$ German Heart Center, \\ Department of Pediatric Cardiology and Adult Congenital Heart Disease, Munich, Germany
}

\section{Keywords}

Congenital heart defect · Fetal cardiac intervention · Fetal echocardiography · Valvuloplasty · Pulmonary atresia with intact ventricular septum

\section{Abstract \\ Introduction: Invasive fetal cardiac intervention (FCl) for pul- monary atresia with intact ventricular septum (PAIVS) and critical pulmonary stenosis (PS) has been performed with}

small single-institution series reporting technical and physiological success. We present the first multicenter experience. Objectives: Describe fetal and maternal characteristics of those being evaluated for $\mathrm{FCl}$, including pregnancy/neonatal outcome data using the International Fetal Cardiac Intervention Registry (IFCIR). Methods: We queried the IFCIR for PAIVS/PS cases evaluated from January 2001 to April 2018 and reviewed maternal/fetal characteristics, procedural details, pregnancy and neonatal outcomes. Data were analyzed using standard descriptive statistics. Results: Of the karger@karger.com

www.karger.com/fdt

Karger
(C) 2020 S. Karger AG, Basel

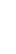

Whitnee J. Hogan

UCSF Benioff Children's Hospital

550 16th Street, 5th Floor, Box 0544

San Francisco, CA 94158 (USA)

Whitnee.hogan@ucsf.edu 
84 maternal/fetal dyads in the registry, 58 underwent pulmonary valvuloplasty at a median gestational age of 26.1 (21.9-31.0) weeks. Characteristics of fetuses undergoing FCI varied in terms of tricuspid valve (TV) size, TV regurgitation, and pulmonary valve patency. There were fetal complications in $55 \%$ of cases, including 7 deaths and 2 delayed fetal losses. Among those who underwent successful $\mathrm{FCl}$, the absolute measurement of the TV increased by $0.32( \pm 0.17) \mathrm{mm} /$ week from intervention to birth. Among 60 liveborn with known outcome, there was a higher percentage having a biventricular circulation following successful $\mathrm{FCl}$ (87 vs. $43 \%$ ). Conclusions: Our data suggest a possible benefit to fetal therapy for PAIVS/PS, though rates of technically unsuccessful procedures and procedure-related complications, including fetal loss were substantial. $\mathrm{FCl}$ criteria are extremely variable, making direct comparison to nonintervention patients challenging and potentially biased. More uniform $\mathrm{FCl}$ criteria for fetuses with PAIVS/PS are needed to avoid unnecessary procedures, expose only fetuses most likely to sustain a benefit, and to enable comparisons to be made with nonintervention patients.

(c) 2020 S. Karger AG, Basel

\section{Introduction}

Critical pulmonary stenosis (PS) or pulmonary atresia with intact ventricular septum (PAIVS) are rare forms of congenital heart disease characterized by right ventricular outflow tract (RVOT) obstruction, varying degrees of right ventricular (RV) hypoplasia, tricuspid valve (TV) hypoplasia, and RV to coronary artery connections, with long-term outcomes ranging from single ventricle palliation to a biventricular circulation [1]. Treatment requires a variety of surgical and trans-catheter interventions early in life. Initial postnatal interventions range from a modified Blalock-Taussig (BT) shunt or ductal stent insertion, in patients who are not candidates for RV decompression, and therefore destined for a single ventricle palliation, to transcatheter radiofrequency perforation and pulmonary balloon valvuloplasty or surgical valvotomy in patients thought to be suitable for an eventual biventricular repair [2-4].

Fetal and postnatal studies have demonstrated that TV size and coronary artery abnormalities are important factors in determining a single versus biventricular circulation $[2,5-10]$. Fetal studies have suggested that a hypoplastic TV $(z$-score $<-3)$ at initial assessment [6, $11]$ as well as a lower rate of TV growth through gestation are associated with a single-ventricle circulation
[6]. Postnatally, a TV $z$-score of $<-5$ has been used as a cut-off for determining single-ventricle circulation [2], but there is variability in cut-off values used in practice [12].

With improvements in fetal echocardiography and catheterization techniques, some centers have begun offering fetal cardiac intervention (FCI) for specific cardiac lesions, including PAIVS and critical (PS). The goal of fetal pulmonary valvuloplasty (FPV) is to decompress the hypertensive RV and promote inflow and outflow of the RV which could result in an improved fetal circulation with growth of the TV and RV, making it amendable to biventricular repair postnatally. Additionally, fetuses with PAIVS or critical PS with significant TR are at risk for developing hydrops and FCI may be used to prevent or reverse hydrops in these cases.

There are small single-institution series that have reported technical and physiological success in promoting achievement of biventricular circulation after birth in PAIVS/PS [13-19], but no multicenter experience has been published. Due to the rarity of FCI, the International Fetal Cardiac Intervention Registry (IFCIR) was created with the intent to compile experience, technical aspects of the cases, and limited outcome data across multiple international centers. The initial IFCIR report included 16 cases of pulmonary valvuloplasty [20]. In this article, we expand the scope of the initial report to describe the first multicenter experience of FCI for PAIVS/PS, including fetal and maternal characteristics of those undergoing FCI, the technical aspects of the procedure, as well as pregnancy and neonatal outcome data.

\section{Methods}

International Fetal Cardiac Intervention Registry

Details of the IFCIR have been described previously [20]. Briefly, it is a voluntary international registry established in 2011 that collects pregnancy, perinatal, operative, and perioperative data for maternal/fetal dyads who were referred to specialist centers for evaluation regarding potential benefit from an FCI. The 254 data fields include demographic information, anatomic diagnosis and characteristics, including ultrasound and echocardiographic findings, operative details including technical success of the procedure, complications incurred at the time of the procedure or during the remaining pregnancy, and pregnancy and neonatal outcome including neonatal procedures and death. Information is de-identified and entered by the local site or centrally by an IFCIR data center representative. Participating IFCIR member sites obtained local Institutional Review Board and ethics board approval or a waiver, governed by applicable local standards. 


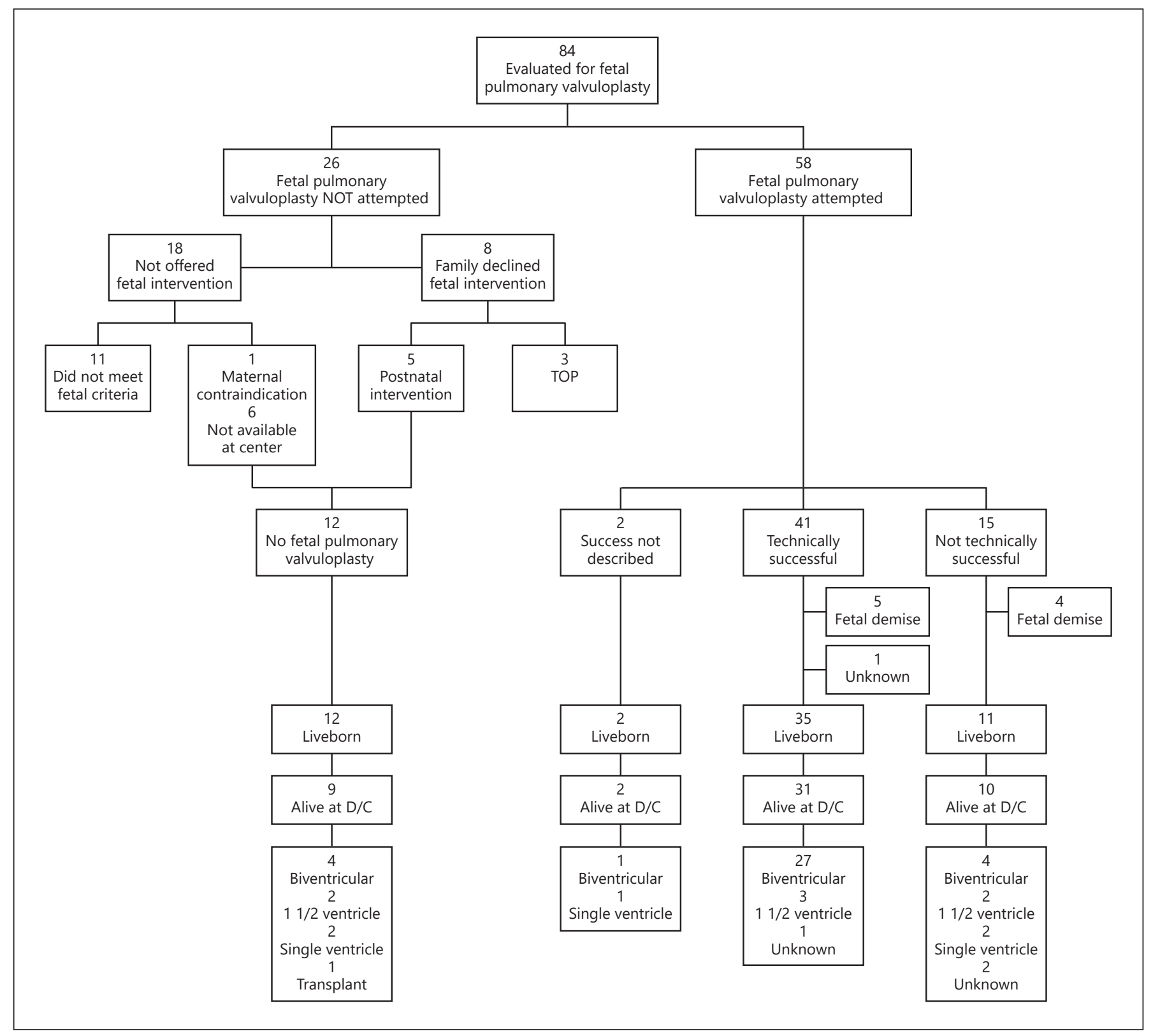

Fig. 1. Fetal pulmonary atresia with intact ventricular septum and pulmonary stenosis. Cases evaluated for fetal pulmonary valvuloplasty in the IFCIR database with pregnancy outcome and ventricular status at last follow-up. TOP, termination of pregnancy.

\section{Case Selection}

For this descriptive analysis, the IFCIR was queried for all cases of "Critical RVOT Obstruction" which included PAIVS and critical PS between January 2001 and April 2018 for possible FCI. There are no currently accepted criteria for FPV in the setting of PAIVS/PS in mid-gestation. Thus, fetuses were considered appropriate candidates for inclusion in this report if they were considered for pulmonary FCI by an institution and either (1) underwent FCI or (2) did not undergo intervention due to noncardiac reasons (e.g., maternal contraindication, patient preference, and others).

\section{Clinical and Echocardiographic Data}

Prenatal clinical data queried included gestational age (GA) at initial consultation, decision regarding fetal intervention, GA at fetal intervention, operative details including medication use, technical success (defined as the balloon being inflated across the RVOT with an increase in forward flow by color and/or new pulmonary insufficiency), complications, and pregnancy outcome. Postnatal clinical data included age at delivery, mode of delivery, cardiac interventions, and postnatal ventricular outcome and survival. 
Table 1. Baseline fetal characteristics (descriptive rather than comparative statistics only)

\begin{tabular}{lccc}
\hline & $\begin{array}{l}\text { All } \\
(n=70)\end{array}$ & $\begin{array}{l}\text { No FCI } \\
(n=12)\end{array}$ & $\begin{array}{l}\text { FCI } \\
(n=58)\end{array}$ \\
\hline $\begin{array}{l}\text { GA echo, weeks } \\
\text { Pulmonary valve }\end{array}$ & $25.4(2.9)$ & $25.7(3.9)$ & $25.2(2.7)$ \\
$\quad$ Size, mm & $4.0(0.8)$ & $4.0(1.2)$ & $4.0(0.7)$ \\
$\quad \begin{array}{l}\text { Z-score } \\
\text { Antegrade flow }\end{array}$ & $-1.5(1.6)$ & $-1.6(3.0)$ & $-1.4(1.2)$ \\
Tricuspid valve & $34(49 \%)$ & $7(58 \%)$ & $27(51 \%)$ \\
$\quad$ Size, mm & $6.4(1.7)$ & $5.4(1.4)$ & $6.7(1.7)$ \\
$\quad \begin{array}{l}\text { Z-score } \\
\text { Degree of tricuspid regurgitation }\end{array}$ & $-1.6(1.7)$ & $-3.0(1.5)$ & $-1.3(1.7)$ \\
$\quad$ None & $2(3 \%)$ & $2(17 \%)$ & 0 \\
$\quad$ Mild & $6(9 \%)$ & $2(17 \%)$ & $4(7 \%)$ \\
$\quad$ Moderate & $12(17 \%)$ & $4(33 \%)$ & $8(14 \%)$ \\
$\quad$ Severe & $37(53 \%)$ & $4(33 \%)$ & $33(57 \%)$ \\
$\quad$ Unknown & $13(18 \%)$ & 0 & $13(22 \%)$ \\
Presence of hydrops & $5(7 \%)$ & $2(17 \%)$ & $3(5 \%)$ \\
\hline
\end{tabular}

Data are presented as mean (SD) or $n(\%)$. FCI, fetal cardiac intervention; GA, gestational age.
Prenatal echocardiographic data queried included GA at initial fetal echo, maximum size of the pulmonary and tricuspid valves, presence of and degree of tricuspid regurgitation (TR), presence of antegrade pulmonary blood flow, and the presence of hydrops (defined as fluid in 2 or more compartments). TR was evaluated by color Doppler assessment as follows: small/narrow jet extending only partly into the receiving chamber as mild, larger/wider jet extending midway or further into the atrium as moderate, and a wider/broad jet with associated right atrial enlargement as severe regurgitation. Pulmonary and tricuspid valve measurements were transformed to $z$-scores with an online calculator which indexed values for GA, using published data [21]. Postnatal echocardiographic data included GA, weight, and length at initial postnatal echo, size of the pulmonary and tricuspid valves, presence of and degree of TR, presence of antegrade pulmonary blood flow, and the presence of hydrops. Postnatal pulmonary and tricuspid valve measurements were transformed to $z$-scores using the Boston Children's Hospital online calculator [22, 23], which indexes values based on infant body surface area.

\section{Statistical Analysis}

Data were analyzed using standard descriptive statistics as appropriate. Means with standard deviations and medians with ranges are reported for continuous variables and frequencies with percentages for categorical variables. Patients with missing data were excluded from analyses involving that variable but were included in the overall reporting as appropriate.

\section{Results}

At the time of the data query in April 2018, there were 84 maternal-fetal dyads evaluated for FPV from a total of 14 international centers, of which FCI was attempted in
58 dyads. Of the 26 not undergoing intervention, 11 were felt not to meet fetal criteria by the individual center, and 15 met fetal criteria but did not undergo intervention (Fig. 1). Of the 8 parents declining intervention, they cited excessive maternal risk in 1 , excessive fetal risk in 2, and financial or geographical reasons in 1 . When excluding those patients that elected for termination and those that were felt not to meet fetal criteria for intervention, there were a total of 58 dyads undergoing FCI and 12 that did not undergo FCI, for a total of 70 cases (Fig. 1).

\section{Fetal Echocardiographic Characteristics}

The echocardiograms at the time of evaluation occurred at a mean GA of $25.4( \pm 2.9)$ weeks. Fetuses undergoing FCI had larger TV annuli and a greater degree of TR than those not undergoing FCI (Table 1); therefore, statistical comparisons were not performed between groups. Descriptive data regarding the FCI fetuses are shown; the mean TV size of those undergoing FCI was $6.7( \pm 1.7) \mathrm{mm}$ which correlated with a mean TV $z$-score of $-1.3( \pm 1.7)$. Of those undergoing FCI, 17/58 (29\%) had a TV $z$-score of $<-2$ and $6 / 58(10 \%)$ had a TV $z$-score $<-3$. Fetuses undergoing FCI had severe TR in 33 (57\%), moderate in $8(14 \%)$, mild in $4(7 \%)$, and unknown in 13 (22\%) cases. There was minimal antegrade pulmonary blood flow at the time of evaluation in $27(51 \%)$ of those undergoing FCI and in 58\% in the non-FCI group. Five fetuses had evidence of hydrops, 3 of which underwent FCI. 
Table 2. Pregnancy and neonatal outcome

\begin{tabular}{|c|c|c|c|c|}
\hline & $\begin{array}{l}\text { All patients } \\
(n=70)\end{array}$ & $\begin{array}{l}\text { No FCI } \\
(n=12)\end{array}$ & $\begin{array}{l}\text { FCI } \\
(n=58)\end{array}$ & $\begin{array}{l}\text { Successful } \\
\text { FCI }(n=41)\end{array}$ \\
\hline \multicolumn{5}{|l|}{ Pregnancy outcome } \\
\hline Term & $49(70 \%)$ & $9(75 \%)$ & $40(69 \%)$ & $29(71 \%)$ \\
\hline Preterm (<37 weeks) & $11(16 \%)$ & $3(25 \%)$ & $8(14 \%)$ & $6(15 \%)$ \\
\hline Fetal death & $2(3 \%)$ & 0 & $2(3 \%)$ & $2(5 \%)$ \\
\hline Periprocedural demise $(<48 \mathrm{~h})$ & $7(10 \%)$ & 0 & $7(12 \%)$ & $3(7 \%)$ \\
\hline Unknown & $1(1 \%)$ & 0 & $1(2 \%)$ & $1(2 \%)$ \\
\hline Delivery, live births, $n$ & $n=60$ & $n=12$ & $n=48$ & $n=35$ \\
\hline Cesarean & $32 / 50(64 \%)$ & $7 / 12(58 \%)$ & $25 / 38(66 \%)$ & $17 / 29(59 \%)$ \\
\hline GA delivery, weeks & $37.5(2.8)$ & $37.3(3.3)$ & $37.6(2.7)$ & $37.4(2.5)$ \\
\hline Birth weight, g & $3,005(664)$ & $3,034(959)$ & $2,997(572)$ & $3,010(482)$ \\
\hline \multicolumn{5}{|l|}{ First postnatal procedure } \\
\hline Pulmonary valvuloplasty & $43(72 \%)^{\mathrm{a}}$ & $8(67 \%)$ & $35(73 \%)$ & $27(77 \%)$ \\
\hline Pulmonary valvotomy & $3(5 \%)$ & $1(8 \%)$ & $2(4 \%)$ & $2(6 \%)$ \\
\hline BT shunt or ductal stent & $3(5 \%)$ & $1(8 \%)$ & $2(4 \%)$ & 0 \\
\hline None & $1(1 \%)$ & 0 & $1(2 \%)$ & $1(3 \%)$ \\
\hline Unknown & $10(17 \%)$ & $2(16 \%)$ & $8(17 \%)$ & $5(14 \%)$ \\
\hline \multicolumn{5}{|l|}{ Neonatal outcome } \\
\hline Alive at discharge & $52 / 59(88 \%)$ & $9 / 12(75 \%)$ & $43 / 47(91 \%)$ & $31 / 34(91 \%)$ \\
\hline \multicolumn{5}{|c|}{ Ventricular status among discharged alive } \\
\hline Biventricular & $36(69 \%)$ & $4(44 \%)$ & $32(74 \%)$ & $27(87 \%)$ \\
\hline $11 / 2$ ventricle & $7(13 \%)$ & $2(22 \%)$ & $5(12 \%)$ & $3(10 \%)$ \\
\hline Single ventricle & $4(8 \%)$ & $1(11 \%)$ & $3(7 \%)$ & 0 \\
\hline Conversion $(2 \mathrm{~V}$ to $1 \mathrm{~V})$ & $1(2 \%)$ & $1(11 \%)$ & 0 & 0 \\
\hline Transplant & $1(2 \%)$ & $1(11 \%)$ & 0 & 0 \\
\hline Unknown & $3(6 \%)$ & 0 & $3(7 \%)$ & $1(3 \%)$ \\
\hline
\end{tabular}

\section{Procedural Details of FCI}

Of the 58 undergoing FCI, the procedure was considered successful in $41(71 \%)$, unsuccessful in $15(26 \%)$, and unknown/not stated in $2(3 \%)$. The median GA at the time of FCI was 26.1 (range 21.9-31.0) weeks. Routine periprocedural tocolysis was used in 23 (49\%) of cases and included nifedipine (20,87\%) and indomethacin $(12,52 \%)$. There was variability in the maternal anesthesia used, with 28 (55\%) receiving intravenous sedation and regional anesthesia, 21 (41\%) receiving local anesthesia, and 2 (4\%) receiving general anesthesia. The vast majority of fetuses (94\%) received fentanyl and neuromuscular blockage for premedication, while $83 \%$ also received atropine, and $6 \%$ received no premedication. There were no maternal complications reported. One or more fetal complications occurred in more than half $(32 / 58,55 \%)$ of the cases, the most common being a pericardial effusion requiring drainage $(28 / 58,48 \%)$ or bradycardia requiring treatment $(21 / 58,36 \%)$. There were 3 cases of a pleural effusion or hemothorax. Procedural death occurred in 3 patients with an additional 4 deaths at $<48 \mathrm{~h}$ following the procedure for a total of 7 periprocedural deaths (12\%).

\section{Fetal Outcome}

All fetal deaths occurred in those undergoing FCI. In addition to the 7 periprocedural deaths, 2 fetuses died $>48 \mathrm{~h}$ following the intervention, for a total of 9 fetal deaths (15.5\%). Both of the late fetal deaths had developed a circular shunt from significant pulmonary insuf- 
Table 3. Postnatal echocardiogram

\begin{tabular}{lccc}
\hline & $\begin{array}{l}\text { All } \\
(n=49)\end{array}$ & $\begin{array}{l}\text { Unsuccessful// } \\
\text { no FCI } \\
(n=20)\end{array}$ & $\begin{array}{l}\text { Successful } \\
\text { FCI } \\
(n=29)\end{array}$ \\
\hline Pulmonary valve & $n=33$ & $n=12$ & $n=21$ \\
$\quad$ Size, mm & $6.3(1.4)$ & $5.9(1.6)$ & $6.6(1.3)$ \\
$Z$-score & $-1.8(1.0)$ & $-1.9(0.7)$ & $-1.8(1.2)$ \\
Antegrade flow & $30(71 \%)$ & $9(56 \%)$ & $21(81 \%)$ \\
Tricuspid valve & $n=38$ & $n=20$ & $n=18$ \\
Size, mm & $9.3(2.4)$ & $8.5(2.6)$ & $9.9(2.2)$ \\
$Z$-score & $-1.0(1.6)$ & $-1.8(1.8)$ & $-0.5(1.4)$ \\
Degree of tricuspid & & & $n=21$ \\
regurgitation & $n=37$ & $n=16$ & $3(14 \%)$ \\
None & $5(13 \%)$ & $2(12 \%)$ & $4(19 \%)$ \\
Mild & $7(19 \%)$ & $3(19 \%)$ & $8(38 \%)$ \\
Moderate & $14(38 \%)$ & $6(38 \%)$ & $6(29 \%)$ \\
$\quad$ Severe & $11(30 \%)$ & $5(31 \%)$ & \\
\hline
\end{tabular}

Data are presented as mean (SD) or $n(\%)$. FCI, fetal cardiac intervention.

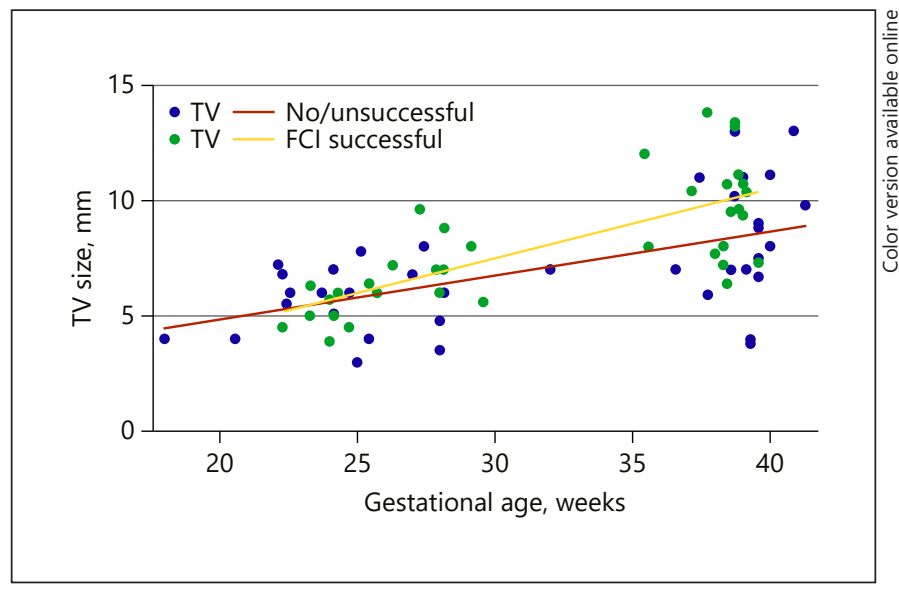

Fig. 2. Change in tricuspid valve (TV) size from prenatal to postnatal evaluation. TV size plotted based on gestational age at preintervention fetal echocardiogram and neonatal echocardiogram in those undergoing successful fetal cardiac intervention (FCI; yellow) and those that did not undergo FCI or it was unsuccessful (red).

\section{Neonatal Outcome}

Of the total 70 cases, there were $60(86 \%)$ live births, 49 of which were term and 11 (18\%) premature. Of those born premature, the median GA at delivery was 34.6 weeks (range 30.0-36.6 weeks). Eight of the $11(73 \%)$ born premature had undergone FCI. The mode of delivery was available in 50 of the patients, with the majority (64\%) undergoing cesarean delivery, regardless of whether FCI was attempted (66\%) or not (58\%). Six neonates required resuscitation at delivery, 1 of which died in the delivery room. Of those who survived the delivery room ( $n=59)$, most $(n=43,73 \%)$ underwent neonatal catheter valvuloplasty, while a surgical pulmonary valvotomy was performed in $3(5 \%)$, and primary BT shunt or ductal stent in $3(5 \%)$. The first postnatal procedure was not reported in $10(17 \%)$ patients. Eighty-seven percent (52/60) of all live births were alive at discharge. The hospital survival rate of the live births was higher in those undergoing FCI than in those that did not (91 vs. $75 \%$ ); however, when fetal deaths $(n=9)$ were included, the survival rates were similar (77 vs. $75 \%$ ).

\section{Ventricular Outcome}

Of the 70 liveborn fetuses, 52 neonates were alive at hospital discharge (Fig. 1). The median age at last assessment was known for 41 neonates, with a median age of 16 months (range 2-192). Of the 52 neonates discharged alive, $36(69 \%)$ had a biventricular circulation, 7 (13\%) 
had a $11 / 2$ ventricle circulation, 5 (10\%) had single-ventricle circulation, and 1 (2\%) had received a primary transplant, with the remaining unknown at the time of last assessment. Of those who underwent successful FCI and were alive at discharge, $27 / 31(87 \%)$ had a biventricular circulation and $3 / 31(10 \%)$ had a $11 / 2$ ventricular circulation. There were no neonates who underwent successful FCI with single ventricle physiology at last assessment, although the ventricular status was unknown for 1 neonate. For liveborn infants, biventricular circulation was achieved more often when FCI was attempted and successful, occurring in $87 \%$ (27/31) of neonates, compared to $43 \%$ (9/21) in those without FCI or with unsuccessful FCI.

\section{Presence of Hydrops}

Of the 5 fetuses with evidence of hydrops at the time of evaluation, 3 underwent successful FCI. One fetus had a demise at 34.4 weeks gestation after FCI. The remaining 4 were born prematurely: the FCI patients at 34.3 and 35.4 weeks, and the non-FCI patients at 30.0 and 31.4 weeks. The only hydropic fetus that survived to discharge had undergone FCI.

\section{Discussion}

This is the first multicenter, international report of fetal valvuloplasty for PAIVS/PS. We confirm that FPV is feasible with a technical success rate of $71 \%$ (41/58), with no reported maternal complications. However, fetal complications were common, occurring in approximately half of the cases, with a periprocedural death rate of $12 \%$ $(7 / 58)$ and total fetal death rate of $15.5 \%(9 / 58)$, which are higher than reports for fetal aortic valvuloplasty [11].

TV diameter $z$-score is commonly used as a measure of right ventricle (RV) cavity size after birth [2]. In neonates, a TV $z$-score between -2.5 and -4.5 corresponds with a borderline RV, and patients with a TV $z$-score $<-5$ exhibit severe RV hypoplasia [2]. In a large recently published study, notable variability in the report of cut-off points for postnatal interventional strategy was observed [12]. To date, most studies in fetuses include a small number of patients. A $z$-score $\leq-3$ at initial fetal assessment has been associated with single ventricle outcome $[6,7$, $13,24]$, but there are scarce data regarding optimal cut-off points for fetal intervention. Some may argue that fetal intervention should only be considered in those fetuses at risk of a single ventricle outcome. In the present study, the mean TV $z$-score at initial fetal echocardiogram in the

Multicenter Report of Fetal Valvuloplasty for PAIVS/PS
FCI group was $-1.3 \pm 1.7$ (range -6.07 to +2.73 ), the TV $z$-score was $<-2$ in only $17 / 58(29.3 \%)$ fetuses and the $z$ score $<-3$ in $6 / 58(10.3 \%)$, suggesting that many of these patients might have had a biventricular outcome even without FCI.

Though this report does not represent a case-control study, it does provide a snapshot of patients referred to and evaluated for potential FCI in specialty centers. The observation that those who underwent successful FCI demonstrated increased growth of the TV through gestation compared to those that did not in this cohort is interesting, though likely biased. The ventricular outcome differed between the unmatched groups, with a higher percentage having a biventricular circulation following successful FCI ( 87 vs. $43 \%$ ). However, the FCI group importantly had less severe TV hypoplasia and more TR at baseline, both of which are predictors for a biventricular outcome. Therefore, it is difficult to conclude if the better outcomes noted in the FCI group are due to this confounding factor or true benefit of the procedure. When examining only fetuses who had FCI, there were some successful FCI cases with an ultimate biventricular circulation that would not have been predicted based on published fetal predictors of ventricular status after birth. For example, when retrospectively applying published predictors for a univentricular outcome, such as TV $z$-score $<-3$ [5] and mild TR, there were fetuses that would have been predicted to be univentricular that underwent successful valvuloplasty with a resultant biventricular or 1 $1 / 2$ ventricular repair. Specifically, there were 4 fetuses with a TV $z$-score $<-3,3$ of which had a biventricular circulation at 24, 40, and 72 months and the other an in utero fetal demise. Three cases had only mild TR, and all had a biventricular circulation, follow-up duration of 16 months for 1 and unknown for the other 2. In comparison, there were 6 fetuses that either did not undergo FCI or it was unsuccessful with a TV $z$-score $<-3$. Of these, 2 had a biventricular circulation, 1 with $11 / 2$ ventricular circulation, 1 single ventricle, 1 was transplanted, and 1 died prior to intervention.

The effect of FCI on TV growth deserves further study. We did not have a control group, but based on prior publications of natural history cohorts, we would not have expected the TV $z$-score to improve. The absolute growth of the TV in PAIVS has been reported to be $0.28 \pm 0.14$ $\mathrm{mm} /$ week in biventricular patients and $0.12 \pm 0.08 \mathrm{~mm} /$ week in single-ventricle patients [6] which is less than what we observed $(0.32 \pm 0.17 \mathrm{~mm} /$ week $)$ in fetuses with a successful valvuloplasty. We also observed an apparent difference in the rate of growth between those who un- 
derwent successful valvuloplasty $(0.32 \pm 0.17 \mathrm{~mm} /$ week $)$ and those who did not $(0.19 \pm 0.15 \mathrm{~mm} /$ week $)$.

One concerning aspect of FPV that was demonstrated in this study is that there continues to be a significant number of patients with intervention-associated complications including fetal demise, mainly due to technical difficulties. The RV in fetuses with PAIVS/PS is often small, trabeculated and hypertrophied, and the RVOT is frequently difficult to visualize, often narrowed, anterior and curved, making the angle of entry quite difficult [25]. In this study, procedural and periprocedural $(<48 \mathrm{~h})$-related fetal complications included a fetal death rate of $12 \%$ and total complication rate of $55 \%$. Restenosis or insufficient dilation of the pulmonary valve can also occur after FPV, and it has been attributed to suboptimal $(<1.1)$ balloon-to-valve ratios, especially in late pregnancy cases [26]. Needles, cannulas, and balloons especially designed for FPV could potentially reduce procedural technical difficulties.

\section{Limitations}

Although this study provides important information regarding FCI in PAIVS/PS, it also demonstrates weaknesses of databases and registries. This registry is voluntary and therefore the data may be biased as it is based on cases and details chosen to be entered into the registry. We did not review ultrasound images but rather relied on measurement data from the individual participating sites. Variation in measurement technique could have introduced variability and error in the TV measurements reported. Moreover, there is a large proportion of missing data which may have biased our conclusions. Though evaluation and procedure-related data are robust, many patients may not deliver at the intervention center and thus due to the lack of complete follow-up data, the registry provides limited and potentially biased data on postnatal clinical status. Additionally, definitive declaration of ventricular status may come several years following intervention, and this registry only presents outcome data collected out to a median of 16 months (range 2-192) and is limited. Patients referred for fetal intervention but who ultimately do not undergo FCI cannot serve as a proper "control" group, and therefore, this is presented as a limited nonintervention group within the registry.

The anatomical and pathophysiological heterogeneity of the disease, the differences in patient selection criteria used between centers performing FCI, and the variability in postnatal management strategies determined by each center's experience make comparing the mid- and longterm outcomes difficult. Future efforts should be directed toward collaborative prospective trials or observational studies with more complete data collection and clear criteria for intervention, generation of best practice guidelines, and evaluation of the effect of these guidelines on the longer-term outcomes for both the mother and fetus.

\section{Conclusion}

Our data suggest that there could be a benefit in promotion of right heart growth associated with fetal therapy for PAIVS/PS, though procedure-related fetal loss and complication rates were substantial, and FCI criteria are extremely variable, making direct comparison to nonintervention patients impossible at present. There is an urgent need for prospective case-controlled studies of fetuses with PAIVS/PS to be established using uniform criteria in order to avoid unnecessary procedures and expose only those most likely to sustain a substantial benefit to the procedural risks involved.

\section{Acknowledgements}

The authors acknowledge the expert assistance of Katie Archbold, Adam Kolesnik, MD, PhD, and Marzena Debska, MD, PhD, and Shabnam Peyvandi, MD, in support of this project and manuscript.

\section{Statement of Ethics}

This research complies with the guidelines for human studies and was conducted ethically in accordance with the World Medical Association Declaration of Helsinki. Participating IFCIR member sites obtained local Institutional Review Board and ethics board approval or a waiver, governed by applicable local standards. Written informed consent was obtained if required by the institution.

\section{Disclosure Statement}

The authors have no conflicts of interest to disclose.

\section{Funding Sources}

No funding was provided for this research.

\section{Author Contributions}

All authors contributed meaningfully to the research, participated in drafting or revision and approval of the final manuscript, and agree to be accountable for the integrity and accuracy of the work. 


\section{References}

1 Daubeney PE, Wang D, Delany DJ, Keeton BR, Anderson RH, Slavik Z, et al.; UK and Ireland Collaborative Study of Pulmonary Atresia with Intact Ventricular Septum. Pulmonary atresia with intact ventricular septum: predictors of early and medium-term outcome in a population-based study. J Thorac Cardiovasc Surg. 2005 Oct;130(4):1071.

2 Alwi M. Management algorithm in pulmonary atresia with intact ventricular septum. Catheter Cardiovasc Interv. 2006 May;67(5): 679-86.

3 Ashburn DA, Blackstone EH, Wells WJ, Jonas RA, Pigula FA, Manning PB, et al.; Congenital Heart Surgeons Study members. Determinants of mortality and type of repair in neonates with pulmonary atresia and intact ventricular septum. J Thorac Cardiovasc Surg. 2004 Apr;127(4):1000-7.

4 Ovaert C, Qureshi SA, Rosenthal E, Baker EJ, Tynan $M$. Growth of the right ventricle after successful transcatheter pulmonary valvotomy in neonates and infants with pulmonary atresia and intact ventricular septum. J Thorac Cardiovasc Surg. 1998 May;115(5):1055-62.

5 Lowenthal A, Lemley B, Kipps AK, Brook MM, Moon-Grady AJ. Prenatal tricuspid valve size as a predictor of postnatal outcome in patients with severe pulmonary stenosis or pulmonary atresia with intact ventricular septum. Fetal Diagn Ther. 2014;35(2):101-7.

6 Salvin JW, McElhinney DB, Colan SD, Gauvreau K, del Nido PJ, Jenkins KJ, et al. Fetal tricuspid valve size and growth as predictors of outcome in pulmonary atresia with intact ventricular septum. Pediatrics. 2006 Aug; 118(2):e415-20.

7 Gardiner HM, Belmar C, Tulzer G, Barlow A, Pasquini L, Carvalho JS, et al. Morphologic and functional predictors of eventual circulation in the fetus with pulmonary atresia or critical pulmonary stenosis with intact septum. J Am Coll Cardiol. 2008 Apr;51(13): 1299-308.

8 Drighil A, Aljufan M, Slimi A, Yamani S, Mathewson J, AlFadly F. Echocardiographic determinants of successful balloon dilation in pulmonary atresia with intact ventricular sep- tum. Eur J Echocardiogr. 2010 Mar;11(2): 172-5.

9 Peterson RE, Levi DS, Williams RJ, Lai WW, Sklansky MS, Drant S. Echocardiographic predictors of outcome in fetuses with pulmonary atresia with intact ventricular septum. J Am Soc Echocardiogr. 2006 Nov;19(11): 1393-400.

10 Roman KS, Fouron JC, Nii M, Smallhorn JF, Chaturvedi R, Jaeggi ET. Determinants of outcome in fetal pulmonary valve stenosis or atresia with intact ventricular septum. Am J Cardiol. 2007 Mar;99(5):699-703.

11 Freud LR, McElhinney DB, Marshall AC, Marx GR, Friedman KG, del Nido PJ, et al. Fetal aortic valvuloplasty for evolving hypoplastic left heart syndrome: postnatal outcomes of the first 100 patients. Circulation. 2014 Aug;130(8):638-45.

12 Awori MN, Mehta NP, Mitema FO, Kebba N. Optimal Z-Score Use in Surgical DecisionMaking in Pulmonary Atresia With Intact Ventricular Septum. World J Pediatr Congenit Heart Surg. 2017 May;8(3):385-8.

13 Tworetzky W, McElhinney DB, Marx GR, Benson CB, Brusseau R, Morash D, et al. In utero valvuloplasty for pulmonary atresia with hypoplastic right ventricle: techniques and outcomes. Pediatrics. 2009 Sep; 124(3):e510-8.

14 Tulzer G, Arzt W, Franklin RC, Loughna PV, Mair R, Gardiner HM. Fetal pulmonary valvuloplasty for critical pulmonary stenosis or atresia with intact septum. Lancet. 2002 Nov; 360(9345):1567-8.

15 Galindo A, Gutiérrez-Larraya F, Velasco JM, de la Fuente P. Pulmonary balloon valvuloplasty in a fetus with critical pulmonary stenosis/atresia with intact ventricular septum and heart failure. Fetal Diagn Ther. 2006; 21(1):100-4.

16 Arzt W, Tulzer G, Aigner M, Mair R, Hafner E. Invasive intrauterine treatment of pulmonary atresia/intact ventricular septum with heart failure. Ultrasound Obstet Gynecol. 2003 Feb;21(2):186-8.

17 Gómez Montes E, Herraiz I, Mendoza A, Galindo A. Fetal intervention in right outflow tract obstructive disease: selection of candidates and results. Cardiol Res Pract. 2012; 2012(1):592403.

18 Pedra SR, Peralta CF, Crema L, Jatene IB, da Costa RN, Pedra CA. Fetal interventions for congenital heart disease in Brazil. Pediatr Cardiol. 2014 Mar;35(3):399-405.

19 Jaeggi E, Renaud C, Ryan G, Chaturvedi R. Intrauterine therapy for structural congenital heart disease: contemporary results and $\mathrm{Ca}$ nadian experience. Trends Cardiovasc Med. 2016 Oct;26(7):639-46.

20 Moon-Grady AJ, Morris SA, Belfort M, Chmait R, Dangel J, Devlieger R, et al.; International Fetal Cardiac Intervention Registry. International fetal cardiac intervention registry: A worldwide collaborative description and preliminary outcomes. J Am Coll Cardiol. 2015 Jul;66(4):388-99.

21 Schneider C, McCrindle BW, Carvalho JS, Hornberger LK, McCarthy KP, Daubeney PE. Development of Z-scores for fetal cardiac dimensions from echocardiography. Ultrasound Obstet Gynecol. 2005 Nov;26(6):599605 .

22 Germanakis I, Sifakis S. The impact of fetal echocardiography on the prevalence of liveborn congenital heart disease. Pediatr Cardiol. 2006 Jul-Aug;27(4):465-72.

23 Boston Children's Hospital Heart Center ZScore Calculator [Internet]. Available from: http://zscore.chboston.org/Home/About.

24 Cao L, Tian Z, Rychik J. Prenatal Echocardiographic Predictors of Postnatal Management Strategy in the Fetus with Right Ventricle Hypoplasia and Pulmonary Atresia or Stenosis. Pediatr Cardiol. 2017 Dec;38(8): 1562-8.

25 Yuan SM. Fetal cardiac interventions: an update of therapeutic options. Rev Bras Cir Cardiovasc. 2014 Jul-Sep;29(3):388-95.

26 Tulzer A, Arzt W, Gitter R, Prandstetter C, Grohmann E, Mair R, et al. Immediate effects and outcome of in-utero pulmonary valvuloplasty in fetuses with pulmonary atresia with intact ventricular septum or critical pulmonary stenosis. Ultrasound Obstet Gynecol. 2018 Aug;52(2):230-7. 